\title{
Chemical Composition and Antimicrobial Activity of Essential Oils of Ocimum basilicum var. album (L.) Benth, Lavandula angustifolia subsp. Angustifolia, Melissa officinalis Belonging to Lamiaceae Family
}

\author{
Hulya Demir $^{1}$ and Sadık Kalaycı ${ }^{2}$ \\ 1. Department of Nutrition and Dietetics, Yeditepe University of Health Sciences, Istanbul, 34755, TR \\ 2. Department of Genetic and Bioengineering, Yeditepe University of Engineering, Istanbul, 34755, TR
}

\begin{abstract}
The present study was conducted to evaluate the chemical composition and antimicrobial activities of essential oils of Ocimum basilicum var. album (L.) Benth, Lavandula angustifolia subsp. angustifolia, Melissa officinalis. The chemical composition of a hydrodistilled essential oils of Ocimum basilicum var. album (L.) Benth., Lavandula angustifolia subsp. angustifolia, Melissa officinalis was analyzed by a GC/MS system. Ocimum basilicum var. album (L.) Benth essential oil contains 1,6-octadien-3-ol,3,7-dimethyl (53.79\%), Lavandula angustifolia subsp. angustifolia essential oil 1,6-octadien-3-ol,3,7-dimethyl (42.07\%), Melissa officinalis essential oil d-limonene (26\%). Antimicrobial screening of the essential oils was made by disc diffusion. The antimicrobial test results showed that the Ocimum basilicum var. album (L.) Benth, Melissa officinalis, Lavandula angustifolia subsp. angustifolia essential oils have great potential of antimicrobial activity against all three (Staphylococcus aureus (ATCC 6338) Gram positive, Escherichia coli (ATCC 10536), Pseudomonas aeruginosa (ATCC 15442) Gram negative bacteria), one fungi (Aspergillus niger), one yeast (Candida albicans) species tested.
\end{abstract}

Key words: Essential oil, GC/MS composition, antimicrobial activity.

\section{Introduction}

Essential oils are composed by secondary metabolites produced in various parts of aromatic plants [1]. Currently, approximately 3,000 essential oils are known, about 300 of which are commercially available [2]. They are colorless compounds that get a dark color over time owing to oxidation. They are a mixture of saturated and unsaturated hydrocarbons, alcohol, aldehydes, esters, ethers, ketones, oxides phenols and terpenes, producing characteristic odors $[3,4]$. In pharmaceutical industry, the essential oils have been used because of its anticancer, antinociceptive, antiphlogistic, antiviral, antibacterial and antioxidant properties [5]. And they also have

Corresponding author: Hulya Demir, PhD, research field: food chemistry. other uses in food and cosmetic industry [6-8]. Lipophilic characteristic of the essential oils is very important in inhibiting the growth of pathogens [1].

Of the 9,000 plant species found in the natural flora of Turkey, 500 are used for medical purposes, and the vast majority of them grow naturally and only a few are cultivated. Basil (Ocimum basilicum L.), lavender (Lavandula angustifolia Mill.) and, melissa (Melissa officinalis L.) belong to Lamiaceae family and grow in Turkeys [9]. The O. basilicum essential oils exhibit a wide and varying array of chemical compounds, depending on variations in chemotypes, leaf and flower colours, aroma and origin of the plants. The chief constituents include chavicol methyl ether or estragole, linalool and eugenol [10]. There is a long tradition of using basil as a medicinal plant in treating coughs, diarrhoea, worm infestations and kidney 
malfunctions [11]. Recent studies even suggest that basil oil displays great potential as a stress repressor [12], and it is also used as a component in drugs for leukaemia treatment [13]. Several Lavandula species are essential oil rich-plants showing high yield values. In food manufacturing, the essential oil of lavandin has been employed in flavoring beverages, ice cream, baked goods, and chewing gum [14]. Lavender oil contains linalool, linalyl acetate, levender, geraniol tannin, flavonoids, and cineol, and has antimicrobial, antifungal, antibiotic, and antidepressant effects [15]. Medical authorities of ancient Greece and Rome mentioned topical Melissa as a treatment for wounds. The herb was later used orally as a treatment for influenza, insomnia, anxiety, depression, and nervous stomach [16]. Melissa officinalis is a well-known medicinal plant species used in perfumes, cosmetics, tea and food products in many countries, and has been reported to possess sedative, spasmolytic and antibacterial properties. Herbal essential oils generally contain a variety of volatile compounds, which may have medicinal properties. It has been reported that $M$. officinalis essential oil has antimicrobial, antioxidative and antitumor properties [17]. A study on $M$. officinalis showed that long-term oral administration of $M$. officinalis essential oil (at an effective dose of $0.04 \mathrm{mg} /$ day) can suppress chemical hyperalgesia in diabetic rats [18].

This study aimed to extract basil (Ocimum basilicum var. album (L.) Benth), lavender (Lavandula angustifolia subsp. angustifolia), and melissa (Melissa officinalis)) essential oils to identify its constituents the compounds from the oil using gas chromatography mass spectrometry (GC-MS) analysis and evaluate it's the antimicrobial activity of the oils.

\section{Materials and Methods}

\subsection{Plant Material}

Ocimum basilicum var. album (L.) Benth plants were collected at the flowering stage from the Oltu valley in eastern Anatolia, Turkey, Lavandula angustifolia subsp. angustifolia, Melissa officinalis plants were collected in southeast of Marmara sea, Bursa, Turkey. The taxonomic identification of plant materials was confirmed by a plant taxonomist, retired Prof. Dr. Hikmet Ozbek, in the Department of Plant Protect, Ataturk University, Erzurum, Turkey. Collected plant materials were dried in the shade, then separated from the stem of the plant.

\subsection{Essential Oil Extraction Preparation}

The aerial parts of the air-dried plants of basil (Ocimum basilicum var. album (L.) Benth), lavender (Lavandula angustifolia subsp. angustifolia), and Melissa (Melissa officinalis) were submitted for $4 \mathrm{~h}$ modified Clevenger collector apparatus. Obtained essential oil was dried over anhydrous sodium sulfate $\left(\mathrm{Na}_{2} \mathrm{SO}_{4}\right)$ and stored at $-4{ }^{\circ} \mathrm{C}$ until tested and analyzed [9]. Qualitative and quantitative analyses of the oils were performed using GC/MS.

\subsection{Test Organisms}

A total of five organisms were tested on the antimicrobial activity. Namely Staphylococcus aureus (ATCC 6338) Gram positive, Escherichia coli (ATCC 10536) and Pseudomonas aeruginosa (ATCC 15442) are Gram negative, Aspergillus nigeris fungus, Candida albicans is a yeast.

\subsection{Determination of Antimicrobial Activity of Essential Oil}

The antimicrobial activity was tested out by disc diffusion method. Discs with $6 \mathrm{~mm}$ in diameter of Whatman No. 1 filter paper were used. Briefly, 100 $\mu \mathrm{L}$ suspension of individual test microorganism was spread homogenously on each plate of mannitol salt agar media. Each disc was soaked with $100 \mu \mathrm{L}$ of pure essential oil and placed on the microbial lawn. Positive control experiments were carried out under similar condition by using ofloxacine for antibacterial activity and nystatin for antifungal activity. Negative control experiments were carried out by using sterile 
Chemical Composition and Antimicrobial Activity of Essential Oils of Ocimum basilicum var. album (L.) 463 Benth, Lavandula angustifolia subsp. Angustifolia, Melissa officinalis Belonging to Lamiaceae Family

water. The tests were repeated three times to ensure reliability. The plates were incubated at $37{ }^{\circ} \mathrm{C}$ for $24 \mathrm{~h}$ and the inhibition zones were checked [19].

\subsection{GC-MS Analysis}

The analysis of the essential oil was performed using a Thermo Finnigan Trace GC/TraceDSQ/A1300 equipped with an SGE-BPX5 MS capillary column (30 m $\times 0.25 \mathrm{~mm}$ id, $0.25 \mu \mathrm{m}$ ). For GC/MS detection an electron ionisation system with an ionisaton energy of $70 \mathrm{eV}$ was used. Helium was the carrier gas at a flow rate of $1 \mathrm{~mL} \cdot \mathrm{min}^{-1}$. Injector and MS transfer line temperatures were set at 220 and $290{ }^{\circ} \mathrm{C}$ respectively. The column temperature was raised from 50 to $150{ }^{\circ} \mathrm{C}$ at a rate of $3{ }^{\circ} \mathrm{C} \cdot \mathrm{min}^{-1}$, held isothermal for $10 \mathrm{~min}$ and finally raised to $250{ }^{\circ} \mathrm{C}$ at $10{ }^{\circ} \mathrm{C} \cdot \mathrm{min}^{-1}$. Diluted samples (1:100 $\mathrm{v} / \mathrm{v}$ in methylene chloride) of $1.0 \mu \mathrm{L}$ were injected manually in splitless mode. The components were identified by comparison of their relative retention times and mass spectra with those of standards, Wiley $7 \mathrm{~N}$ library data of the GC/MS system and literature data [19]. The results were also confirmed by comparison of the elution order of the compounds with their relative retention indices on non-polar phases reported in the literature [19].

\section{Results}

\subsection{Antimicrobial Activity of Essential Oil}

The essential oil exhibited antimicrobial activity against Gram negative, Gram positive, fungus and yeast. Discs $(6 \mathrm{~mm})$ containing $100 \mu \mathrm{L}$ essential oil were subjected to five microbial strains individually. Among the tested microbial strains, strong inhibition effect was found against all of them.

\subsection{Chemical Composition of Essential oil of Ocimum basilicum var. album (L.) Benth}

The GC-MS analysis of the Ocimum basilicum var. album (L.) Benth essential oil led to identification of 48 different compounds. The total compounds percentage was $100 \%$. 1,6-octadien-3-ol,3,7-dimethyl
(53.79\%), 3-Allyl-6-methoxyphenol (12.57\%), eucalyptol(1,8-cineole) (4.33\%), $\alpha$-muurolol (3.87\%) were major compounds (Table 1 ).

\subsection{Chemical Composition of Essential Oil of Melissa officinalis}

The GC-MS analysis of the Melissa officinalis essential oil leads to identification of 48 different compounds. The total compounds percentage was 100\%: D-limonene (26.00\%), citral (14.93\%), neral (13.60\%), caryophyllene oxide (11.45\%), benzene,1-(1,5-dimethyl-4-hexenyl)-4-methyl (6.97\%) were major compounds (Table 2).

3.4 Chemical Composition of Essential Oil of Lavandula angustifolia subsp. angustifolia

The GC-MS analysis of the Lavandula angustifolia L. essential oil led to identification of 48 different compounds. The total compounds percentage was 100\%. 1,6-octadien-3-ol,3,7-dimethyl (42.07\%), linalyl acetate (18.26\%), camphor (5.89\%), alpha-terpineol (4.83\%), geranyl acetate (2.56\%) were major compounds (Table 3).

\section{Discussion}

Table 1 lists the chemical composition of the essential oils of Ocimum basilicum var. album (L.) Benth. The major compound of Ocimum basilicum var. album (L.) Benthoil is 1,6-octadien-3-ol,3,7-dimethyl (53.79\%). In addition to 3-Allyl-6-methoxyphenol (12.57\%), eucalyptol (1,8-cineole) (4.33\%), and $\alpha$-muurolol (3.87\%) as major constituents. However, we found very low levels of bicyclo[3.1.1]hept-2-ene,2,6-dimethyl-6-(4-methyl-3pentenyl)-, alfa-humulene, bicyclogermacrene: $1.72 \%$, $1.02 \%$ and $0.85 \%$, respectively. Ref. [10] reported that the content of essential oil in Egypt basil varieties was from 0.3 to $0.7 \%$. Nineteen compounds, representing $96.7 \%$ of the total oil were identified. The main components were as follows: linalool (48.4\%), 1,8-cineol (12.2\%), eugenol (6.6\%), methyl cinnamate 
Table 1 Chemical composition of essential oil of Ocimum basilicum var. album (L.) Benth.

\begin{tabular}{|c|c|c|c|}
\hline $\mathrm{N}$ & R. time & Compound & $\%$ \\
\hline 1 & 8.398 & hex-2(E)-enal & 0.08 \\
\hline 2 & 11.744 & alpha-pinene & 0.33 \\
\hline 3 & 12.345 & camphene & 0.15 \\
\hline 4 & 13.458 & sabinene & 0.17 \\
\hline 5 & 13.543 & $\beta$-pinene & 0.44 \\
\hline 6 & 14.270 & Myrcene & 0.50 \\
\hline 7 & 15.768 & d-limonene & 0.50 \\
\hline 8 & 15.863 & 1,8-cineole (eucalyptol) & 4.33 \\
\hline 9 & 16.205 & cis-ocimene & 0.06 \\
\hline 10 & 16.613 & (E)-beta-ocimene & 0.66 \\
\hline 11 & 16.996 & gamma-terpinene & 0.06 \\
\hline 12 & 17.707 & linalool oxide & 0.47 \\
\hline 13 & 18.151 & 1,3,3-Trimethylbicyclo[2.2.1]heptan-2-ol & 1.11 \\
\hline 14 & 18.328 & trans-linalool oxide & 0.46 \\
\hline 15 & 19.109 & 3,7-Dimethyl-1,6-octadien-3-ol & 53.79 \\
\hline 16 & 20.431 & $(+)$-2-bornanone & 2.28 \\
\hline 17 & 22.436 & 1-methoxy-4-(2-propenyl)benzene & 1.49 \\
\hline 18 & 27.743 & alfa-cubebene & 0.09 \\
\hline 19 & 28.185 & 3-Allyl-6-methoxyphenol & 12.57 \\
\hline 20 & 28.648 & copaene & 0.18 \\
\hline 21 & 28.940 & beta-bourbonene & 0.26 \\
\hline 22 & 29.172 & beta-elemene & 1.47 \\
\hline 23 & 29.547 & 1,2-Dimethoxy-4-(2-methoxyethenyl)benzene & 2.14 \\
\hline 24 & 30.063 & trans(beta)-caryophyllene & 0.31 \\
\hline 25 & 30.557 & bicyclo[3.1.1]hept-2-ene,2,6-dimethyl-6-(4-methyl-3-pentenyl)- & 1.72 \\
\hline 26 & 30.658 & alpha-guaiene & 0.64 \\
\hline 27 & 30.909 & (+)-epi-bicyclosesquiphellandrene & 0.11 \\
\hline 28 & 31.155 & alpha-humulene & 1.02 \\
\hline 29 & 31.434 & (+)-epi-bicyclosesquiphellandrene & 0.45 \\
\hline 30 & 31.547 & italicene & 0.06 \\
\hline 31 & 32.009 & d-dermacrene & 1.15 \\
\hline 32 & 32.088 & farneseneE-beta & 0.18 \\
\hline 33 & 32.166 & beta-selinene (CAS) & 0.16 \\
\hline 34 & 32.483 & bicyclogermacrene & 0.85 \\
\hline 35 & 32.759 & azulene, 1,2,3,4,5,6,7,8-octahydro-1,4-dimethyl-7-(1-methylethenyl)-, (1S,4S,7R)- & 1.08 \\
\hline 36 & 33.018 & naphthalene, 1,2,3,4,4a,5,6,8a-octahydro-7-methyl-4-methylene-1-(1-methylethyl) & 2.09 \\
\hline 37 & 33.258 & naphthalene, 1,2,3,5,6,8a-hexahydro-4,7-dimethyl-1-(1-methylethyl)-, (1S-cis)-. & 0.48 \\
\hline 38 & 33.693 & naphthalene, 1,2,4a,5,8,8a-hexahydro-4,7-dimethyl-1-(1-methylethyl)- & 0.05 \\
\hline 39 & 35.071 & caryophyllene oxide & 0.08 \\
\hline 40 & 35.195 & alloaromadendrene oxide & 0.08 \\
\hline 41 & 35.383 & salvial-4(14)-en-1-one & 0.06 \\
\hline 42 & 35.839 & 12-oxabicyclo[9.1.0]dodeca-3,7-diene,1,5,5,8-tetramethyl & 0.18 \\
\hline 43 & 37.517 & alfa-muurolol & 3.87 \\
\hline 44 & 38.035 & 3-methyl-5-propyl-4-butylidene-cyclohex-2-ene-1-one & 0.89 \\
\hline 45 & 38.605 & tetradecanal & 0.07 \\
\hline 46 & 42.028 & phytone & 0.08 \\
\hline 47 & 44.982 & n-hexadecanoic acid & 0.16 \\
\hline 48 & 49.122 & 9-octadecenoic acid & 0.25 \\
\hline
\end{tabular}


Chemical Composition and Antimicrobial Activity of Essential Oils of Ocimum basilicum var. album (L.) 465 Benth, Lavandula angustifolia subsp. Angustifolia, Melissa officinalis Belonging to Lamiaceae Family

Table 2 Chemical composition of essential oil of Melissa officinalis.

\begin{tabular}{|c|c|c|c|}
\hline $\mathrm{N}$ & R. time & Compound & $\%$ \\
\hline 1 & 11.740 & $\alpha$-pinene & 0.58 \\
\hline 2 & 13.453 & Sabinene & 1.10 \\
\hline 3 & 14.126 & 6-methyl-5-hepten-2one & 2.22 \\
\hline 4 & 14.275 & Myrcene & 0.41 \\
\hline 5 & 15.911 & d-limonene & 26.00 \\
\hline 6 & 18.563 & 3-methyl-2-(2-methyl-2-butenyl)-furan & 0.27 \\
\hline 7 & 18.758 & z-citral & 0.46 \\
\hline 8 & 18.844 & 3,4,4-trimethyl-2-cyclopenten-1-one & 0.24 \\
\hline 9 & 19.944 & 7-Oxabicyclo[4.1.0]heptane,1-methyl-4-(1-methylethenyl) & 0.21 \\
\hline 10 & 20.127 & $(+)$-E-limonene oxide & 0.69 \\
\hline 11 & 20.572 & trans-chrysanthemal & 0.37 \\
\hline 12 & 20.724 & Citronella & 0.16 \\
\hline 13 & 21.577 & 2-(2',3'-Epoxy-3'-methylbutyl)-3-methylfuran & 0.75 \\
\hline 14 & 21.847 & Verbenol & 0.81 \\
\hline 15 & 22.325 & (S)-(-)-(4-1sopropenyl-1-cyclohexenyl)methanol & 0.75 \\
\hline b16 & 22.452 & santolina triene & 0.33 \\
\hline 17 & 24.115 & Neral & 13.60 \\
\hline 18 & 24.480 & Piperitone & 0.21 \\
\hline 19 & 25.197 & Citral & 14.93 \\
\hline 20 & 28.197 & neryl acetate & 0.31 \\
\hline 21 & 28.639 & Copaene & 0.86 \\
\hline 22 & 28.848 & geranyl acetate & 2.37 \\
\hline 23 & 28.941 & $\beta$-bourbonene & 0.67 \\
\hline 24 & 29.838 & 1H-3a,7-methanoazulene,2,3,4,7,8,8a-hexahydro-3,6,8,8-tetramethyl & 0.82 \\
\hline 25 & 30.084 & $\operatorname{trans}(\beta)$-caryophyllene & 0.92 \\
\hline 26 & 31.150 & $\alpha$-humulene & 0.33 \\
\hline 27 & 31.377 & Neoalloocimene & 0.92 \\
\hline 28 & 31.707 & geranyl propanoate & 0.57 \\
\hline 29 & 31.845 & $\gamma$-cadinene & 0.21 \\
\hline 30 & 32.052 & benzene,1-(1,5-dimethyl-4-hexenyl)-4-methyl & 6.97 \\
\hline 31 & 32.453 & Bicyclogermacrene & 0.17 \\
\hline 32 & 32.793 & $\beta$-bisabolene & 0.15 \\
\hline 33 & 32.886 & $\alpha$-cedrene & 0.19 \\
\hline 34 & 33.005 & naphthalene,1,2,3,4,4a,5,6,8a-octahydro-7-methyl-4-methylene-1-(1-methylethyl)- & 0.72 \\
\hline 35 & 33.267 & Deltacadinene & 0.33 \\
\hline 36 & 33.697 & naphthalene,1,2,4a,5,6,8a-hexahydro-4,7-dimethyl-1-(1-methylethyl) & 0.25 \\
\hline 37 & 34.167 & caryophyllene oxide & 0.39 \\
\hline 38 & 35.187 & caryophyllene oxide & 11.45 \\
\hline 39 & 35.289 & benzenebutanoic acid,2,5-dimethyl-,methyl ester & 0.37 \\
\hline 40 & 35.428 & benzenebutanoic acid,2,5-dimethyl-,methyl ester & 0.28 \\
\hline 41 & 35.575 & 1H-Cycloprop[e]azulen-7-ol,decahydro-1,1,7-trimethyl-4-methylene & 1.94 \\
\hline 42 & 35.864 & 12-oxabicyclo[9.1.0]dodeca-3,7-diene,1,5,5,8-tetramethyl- & 1.24 \\
\hline 43 & 36.684 & 2,6-octadienoic acid,3,7-dimethyl-,methyl ester & 0.27 \\
\hline 44 & 37.110 & 1H-benzocyclohepten-7-ol,2,3,4,4a,5,6,7,8-octahydro-1,1,4a,7-tetramethyl- & 0.15 \\
\hline 45 & 42.029 & Phytone & 0.28 \\
\hline 46 & 44.963 & n-hexadecanoic acid & 0.21 \\
\hline 47 & 48.458 & 4-methyl-5-(3methyl-2-butenyl)-6-methyl-1-formyl-6-(4methyl-3-penten) & 0.16 \\
\hline 48 & 49.105 & cis-vaccenic acid & 0.44 \\
\hline
\end{tabular}


Table 3 Chemical composition of essential oil of Lavandula angustifolia subsp. angustifolia.

\begin{tabular}{|c|c|c|c|}
\hline $\mathrm{N}$ & R. time & Compound & $\%$ \\
\hline 1 & 7.412 & hexane,1-methoxy-(CAS) & 0.10 \\
\hline 2 & 11.742 & alpha-pinene & 0.17 \\
\hline 3 & 12.342 & Camphene & 0.24 \\
\hline 4 & 13.456 & Sabinene & 0.05 \\
\hline 5 & 14.086 & beta-pinene & 0.16 \\
\hline 6 & 14.086 & 3-octanone (CAS) & 0.64 \\
\hline 7 & 14.280 & Myrcene & 1.30 \\
\hline 8 & 14.923 & herboxide second isomer & 0.07 \\
\hline 9 & 15.250 & hexyl-ethanoate & 0.86 \\
\hline 10 & 15.590 & para-cymene & 0.06 \\
\hline 11 & 15.770 & cyclohexene,1-methyl-5-(1-methylethenyl)- & 0.97 \\
\hline 12 & 15.870 & eucalyptol(1,8-cineole) & 3.73 \\
\hline 13 & 16.214 & alfa-pinene & 1.08 \\
\hline 14 & 16.627 & (E)-beta-ocimene & 1.57 \\
\hline 15 & 17.677 & linalool oxide & 2.11 \\
\hline 16 & 18.178 & alpha-terpinolene & 0.33 \\
\hline 17 & 18.325 & trans-linalool oxide & 1.64 \\
\hline 18 & 19.113 & 1,6-octadien-3-ol,3,7-dimethyl & 42.07 \\
\hline 19 & 19.726 & cyclobutanecarboxylic acid, octyl ester & 0.13 \\
\hline 20 & 19.847 & Alloocimene (CAS) & 0.06 \\
\hline 21 & 20.478 & Camphor & 5.89 \\
\hline 22 & 20.604 & propanoic acid,2-methyl-,hexyl ester (CAS) & 0.29 \\
\hline 23 & 20.680 & Lilac aldehyde B & 0.06 \\
\hline 24 & 20.814 & 2H-pyran,3,6-dihydro-4-methyl-2-(2-methyl-1-propenyl) & 012 \\
\hline 25 & 21.966 & 2-cyclohexen-1-one,4-(1-methylethyl) & 0.17 \\
\hline 26 & 22.254 & hexyl-butyrate & 2.01 \\
\hline 27 & 22.535 & alpha-terpineol & 4.83 \\
\hline 28 & 22.933 & acetic acid,2-ethylhexyl ester (CAS) & 1.33 \\
\hline 29 & 23.270 & gamma-terpinene & 0.32 \\
\hline 30 & 23.505 & isobornyl formate & 0.29 \\
\hline 31 & 23.840 & hexyl 2-methyl butyrate & 0.24 \\
\hline 32 & 23.920 & benzaldehyde, 4-(1-methylethyl) & 0.10 \\
\hline 33 & 24.013 & butanoate hexyl-,3-methyl- & 0.29 \\
\hline 34 & 24.678 & linalyl acetate & 18.26 \\
\hline 35 & 25.046 & Citral & 0.07 \\
\hline 36 & 25.597 & endobornyl acetate & 0.08 \\
\hline 37 & 25.759 & lavandulyl acetate & 0.08 \\
\hline 38 & 27.081 & hexyl tglate & 0.60 \\
\hline 39 & 27.793 & linalool & 0.08 \\
\hline 40 & 28.215 & neryl acetate & 1.42 \\
\hline 41 & 28.810 & geranyl acetate & 2.56 \\
\hline 42 & 30.070 & trans-beta-caryophyllene & 0.42 \\
\hline 43 & 31.160 & (E)-beta-farnesene & 0.28 \\
\hline 44 & 31.994 & D-germacrene & 0.13 \\
\hline 45 & 32.784 & neryl(S)-2-methylbutanoate & 0.18 \\
\hline 46 & 35.077 & caryophyllene oxide & 0.47 \\
\hline 47 & 44.962 & n-hexadecanoic acid & 0.07 \\
\hline \multirow[t]{2}{*}{48} & 49.121 & 9-octadecenoic acd, E & 0.27 \\
\hline & & & 100 \\
\hline
\end{tabular}


(6.2\%), $\alpha$-cubebene (5.7\%), caryophyllene (2.5\%), $\beta$-ocimene (2.1\%) and $\alpha$-farnesene (2.0\%). The tested oil showed significant antifungal activity that was dependent on the used oil concentration. Differences in basil essential oil content between this study and another report from research conducted in Egypt could be due to diffential environmental conditions Egypt and Turkey. It has been demonstrated that basil essential oil can vary depending on growth conditions [20]. In a study conducted in Australia, the morphological characteristics, yield and essential oil components of 5 different varieties of basil were investigated. Researchers have reported that plant length varies from 39 to $61 \mathrm{~cm}$, single plant weights vary from 80 to $499 \mathrm{~g}$, and total plant weights vary from 448 to $1,624 \mathrm{~kg} / \mathrm{d}$, and the components of the varieties are different according to the results of the gas chromatography analysis and that the main components of the essential oils are methyl chavicol, linalol, 1,8-sineol [21].

In another study, the chemical compositions of essential oils of the two types of basil grown in Turkey were examined. Essential oils of over-ground parts of plants were obtained and their components were determined by GC-MS.

Korucu [22] found that the highest amounts of essential oil components in fresh basil samples were linalol (16.67\%-25.58\%) and eugenol (7.31\%-12.64\%) while [23] found that ladenein was between $11.79 \%-30.07 \%$, pilosin was between 1.99\%-7.24\%, genkwan was between $2.38 \%-5.16 \%$, salvigen was between $2.29 \%-4.32 \%$, cirsiliol was between $1.42 \%-26.01 \%$, and apigenin was between $4.5 \%-5.35 \%$. In one study, they found that the essential oil ratio of the basil flower varies between $0.13 \%$ and $1.23 \%$, while essential oil content of its leaf varies between $0.18 \%$ and $1.70 \%$. The main components of essential oil were methyl chavicol and eugenol [24].

In our study, we found that S. aureus, E. coli, P. aeruginosa, A. nigerand, C. Albicans are inhibited by the essential oils of $O$. basilicum L. This can be explained by the fact that the oil acts on the bacterial membrane. Monoterpenes or sesquiterpene hydrocarbons and their oxygenated derivatives exhibit a potential antimicrobial activity [25]. Ref. [10] showed that compounds of $O$. basilicum essential oil such as linalool, 1,8-cineol, eugenol, methyl cinnamate and $\alpha$-cubebene were among the main components present. The antimicrobial activity of an essential oil is attributed mainly to its major compounds. However, the synergistic and antagonistic effect of one compound in minor percentage in the mixture has to be considered. Some researchers reported that there is a relationship between the chemical structures of the most abundant compounds in the essential oils and the antimicrobial or antifungal activities [26].

Table 2 lists the chemical composition of the essential oils of Melissa officinalis. The major compound of Melissa officinalis oil is d-limonene (26.00\%), following by citral (14.93\%), neral (13.60\%), caryophyllene oxide (11.45\%), and benzene,1-(1,5-dimethyl-4-hexenyl)-4-methyl (6.97\%). However, we found very low levels of 6-methyl-5-hepten-2one, geranyl acetate, 1H-Cycloprop[e]azulen-7-ol,decahydro-1,1,7-trimethy l-4-methylene: $2.22 \%, 2.37 \%$ and $1.94 \%$, respectively.

In the research of Ref. [27], (E)-citral (37.2\%), neral (23.9\%) and citronella (20.3\%) have the highest percentages (81.4\%) among the 14 components identified. $M$. officinalis L. has a strong lemon odour, which may be due in large part to (E)-citral. (E)-citral is not optically active and is a principal component of lemon grass oil. This compound has been utilized in perfumes, as a flavouring agent, and as an intermediate for other fragrances and vitamin A synthesis. The pure form of neral is a colourless liquid and has a rose-neroli odour.

This compound is utilized for perfumery and flavouring. Citronellal has both d- and l-isomers [27]. Biological and aromatic effects of the main and minor 
compounds of the essential oil of $M$. officinalis $\mathrm{L}$. have high importance in term of their possible use in medicine, cosmetics and foods [28].

The obtained essential oil is rich in monoterpenes and sesquiterpenes. The main compounds of volatile oil are citral (geranial, neral) and citronellal, giving the characteristic lemon odor to the oil. Other ingredients arebenzoic acids (gallic acid, protocatechuic acid), flavonoids (apigenin, luteolin), triterpenes (ursolic acid, oleanolic acid) and phenylpropanoyl glycosides [29, 30]. Ref. [21] reported that thirty three components were identified representing $89.30 \%$ of the total oil in leaves composition. Six predominant components followed in the essential oils from Melissa officinalis were citronellal (14.40\%), isogeraniol (6.40\%), geraniol acetate (10.20\%), nerolecetate (5.10\%), caryophyllene (8.10\%) and caryophyllene oxide (11.00\%), representing $55.20 \%$ of the total oil [24]. However, the age of Melissa officinalis plant effected the concentration of other constituents and the proportions of the following compounds were subject to especially high fluctuations: citronellal $(8.7 \%$ and $0.4 \%)$, geraniol (trace amounts and 0.6\%), and geranyl acetate $(0.5 \%$ and $3.0 \%)$, as well as, among others, isogeranial, E-caryophyllene oxide, germacrene $\mathrm{D}$, and carvacrol [31].

In the essential oil of Melissa officinalis ssp inodora, sesquiterpenes such as alpha-kubeben, beta-cariophilene and alpha-kadinol were found as main components [32].

Melissa officinalis plant has sedative, carminative, antimicrobial and topical antiviral effects. It is used internally for nervous sleep problems, anxiety, unrest, irritability and functional gastrointestinal disorders [33, 34]. Other study showed that $M$. officinalis essential oil has anti-bacterial, anti-fungal, anti-parasitic and anti-histaminic activities [35]. Thanks to its anti-microbial effect, it has a preventive effect on the growth of yeasts which cause the food degradation in the food industry [36].
In a study in German, N. Catariave M. officinalis essential oils have been researched for antibacterial activities against bacteria that affect the respiratory system and cause skin infections. The highest antibacterial activity in all the bacteria used belonged to $M$. officinalis essential oil. In particular, $M$. officinalis essential oil was found to be the most effective one against Streptococcus pneumoniae strain with the lowest MIC value [37].

In a study using disk diffusion method on essential oil obtained by hydrodistillation from the aerial parts of the plant, it was found that essential oil was effective against all gram positive and gram negative bacterial strains tested at different ratios and showed high antimicrobial activity especially on Sigellasonei which is a very resistant bacterium and E. coli [38].

As seen in Table 3, the major compound of Lavandula angustifolia Mill. oil is 1,6-octadien-3-ol,3,7-dimethyl (42.07\%). In addition to linalyl acetate (18.26\%), camphor (5.89\%), alpha-terpineol (4.83\%), and eucalyptol (1,8-cineole) (3.73\%) as major constituents. However, we found very low levels of geranyl acetate, linalool oxide, acetic acid, and 2-ethylhexyl ester (CAS): 2.56\%, $2.11 \%$, and $1.33 \%$, respectively.

Results of other studies indicated that the essential oil of lavandula from Iranian contains 1,8-cineole (47.94\%), borneol (26.14\%), camphor (14.4\%), while the essential oil lavandula from Romania contains camphor (32.7\%) and eucalyptol (26.9\%) [39]. In the other reports, linalool and linalyl acetate were the major components of the essential oil of Hungarian lavandula [40].

Essential oils of the Lavandula species (lavender) exhibit various biological activities, namely anti-microbial, antimutagenic, anti-inflammatory and analgesic properties [41]. Chemical components of plants are determined by a series of factors, including plant genetic,climate, edaptic, elevation, topography, and also by interaction of various factors [14].

The principal compound of the essential oil from $L$. 
angustifolia (Croatia) is linalool (66.83\%), while for the same species grown in France, this compound only represents $37.31 \%$ of the chemical composition of the oil, being curcuminaldehyde (41.32\%) the major component. Moreover, the oil of the same Lavandula species (L. angustifolia) grown at high altitude in France also presents a great amount of linalool (23.49\%), but with linalylformate (41.72\%) being the most abundant compound. The main compounds of the other Lavandulaspecies from Croatia (L. officinalis) are linalool (47.86\%), linalyl formate (22.09\%), and limonene (14.78\%) [26]. Linalool and linalyl acetate have maximum and great absorbing properties from skin during massage with a depression of central nervous system. Linalool shows sedative effects and linalyl acetate shows marked narcotic actions. These two actions may be responsible for its use in lavender pillow anxiety patients with sleep disputance pattern, improving the felling of well being, supporting mental alertness and suppressing aggression and anxiety [42].

\section{Conclusion}

Most of the essential oils obtained from plants form terpene type compounds. Terpen type compounds are used in many fields such as medicines, cosmetics, perfumery, food because of their pleasant smells and their high biological activity. Similar studies have to be done and increased to find plants containing these compounds in high proportion.

Antimicrobial resistance in bacteria is increasing rapidly. In contrast, bacteria do not gain resistance to plant and plant products that show antimicrobial properties. The reason for this is that synthetically produced medicines are made by isolating any active substance in plants. Bacteria can neutralize medicines by creating resistant breeds against synthetic drugs containing a single structure in time.

On the other hand, since the active substances in plants are in a complex structure with other substances, it is difficult for bacteria to develop resistance against this structure. Therefore, as an alternative to antibiotics, it may be appropriate to increase the number of researches for the use of plants and herbal products as traditional antibiotics. At the same time, the use of plants and herbal products is advantageous in this respect because of the higher number of side effects of synthetically derived materials. However, especially the more detailed results obtained by purely obtaining essential oil components or their main groups and testing them on microorganisms may be even more enlightening.

\section{References}

[1] Lanciotti, R., Gianotti, A., Patrignani, F., Belletti, N., Guerzoni, M. E., and Gardini, F. 2004. "Use of Natural Aroma Compounds to Improve Shelf Life and Safety of Minimally Processed Fruits.” Trends Food Sci. Tech. 15: 201-8.

[2] Shaaban, H., A. E., El-Ghorab, A. H., and Shibamoto, T. 2012. "Bioactivity of Essential Oils and Their Volatile Aroma Components: Review.” J. Essenr Oil Res. 24: 203-12.

[3] Schiller, J., Süß, S., Petković, M., Hanke, G., Vogel, A., and Arnold, K. 2002. "Effects of Thermal Stressing on Saturated Vegetable Oils and Isolated Triacylglycerols: Product Analysis by MALDI-TOF Mass Spectrometry, NMR and IR Spectroscopy.” 104 (8): 496-505.

[4] Wildwood, C. 1996. The Encyclopedia of Aromatherapy. Rochester: Healing Arts Press. 36-Bahtiyarca, R., and Bagdat, B. C. 2006. "The Essential Oil of Lemon Balm (Melissa officinalis L.), Its Components and Using Fields.” J. Fac. Agric. 21 (1): 116-21.

[5] Sun, J., Wang, X., Wang, P., Li, L., Qu, W., and Liang, J. 2015. “Antimicrobial, Antioxidant and Cytotoxic Properties of Essential Oil from Dictamnus Angustifolius.” J. Ethnopharmacol 159: 296-300.

[6] Riahi, L., Elferchichi, M., Ghazghazi, H., Jebali, J., Ziadi, S., Aouadhi, C., et al. 2013. "Phytochemistry, Antioxidant and Antimicrobial Activities of the Essential Oils of Mentha rotundifolia L. in Tunisia.” Ind. Crops. Prod. 49: 883-9.4-Yap, P. S. X., Krishnan, T., Yiap, B. C., Hu, C. P., Chan, K. G., and Lim, S. H. E. 2014. "Membrane Disruption and Anti-quorum Sensing Effects of Synergistic Interaction between Lavandula angustifolia (Lavender Oil) in Combination with Antibiotic against Plasmid-Conferred Multi-drug-resistant Escherichia coli.” J. Appl. Microbiol. 116: 1119-28.

[7] Ma, T., Luo, J., Tian, C., Sun, X., Quan, M., Zheng, C., et al. 2015. "Influence of Technical Processing Units on 
470 Chemical Composition and Antimicrobial Activity of Essential Oils of Ocimum basilicum var. album (L.) Benth, Lavandula angustifolia subsp. Angustifolia, Melissa officinalis Belonging to Lamiaceae Family

Chemical Composition and Antimicrobial Activity of Carrot (Daucus carrot L.) Juice Essential Oil.” Food Chem. 394-400.

[8] Muriel-Galet, V., Cran, M. J., Bigger, S. W., Hernandez-Munoz, P., and Gavara, R. 2015. “Antioxdant and Antimicrobial Properties of Ethylene Vinyl Alcohol Opolymer Films Based on the Release of Oregano Essential Oil and Green Tea Extract Components.” J. Food Eng.149: 9-16.

[9] Sahin, F., Gulluce, M., Daferera, D., Sokman, A., Sokman, M., Polissiou, M., Agar, G., and Ozer, H. 2004. "Biological Activities of the Essential Oils and Methanol Extract of Organum vulgare ssp. vulgare in the Eastern Anatolia region of Turkey.” Food Control 15: 549-57.

[10] Abou El-Soud, N. H.,Deabes, M., Abou El-Kassem, L., and Khalil, M. 2012. "Chemical Composition and Antifungal Activity of Ocimum basilicum L. Essential Oil.” Macedonian Journal of Medical Sciences 3 (3): 374-9.

[11] Holm,Y. 1999. Bioactivity of Basil. Edited by R. Hiltunen, and Y. Holm, Basil: The Genus Ocimum. Harwood Academic Publishers. Amsterdam, pp. 113-35.

[12] Nakamura, A., Fujiwara, S., Matsumoto, I., and Abe, K. 2009. "Stress Repression in Restrained Rats by (R)-(-)-Linalool Inhalation and Gene Expression Profiling of Their Whole Blood Cells.” J. Agric. Food Chem. 57: 5480-5. Suschke, U., Sporer, F., Schneele, J., Geiss, H. K., and Reichling, J. 2007. "Antibacterial and Cytotoxic Activity of Nepeta cataria L., N. cataria var. citriodora (Beck.) Balb. and Melissa officinalis L. Essential Oils.” Nat. Prod. Commun 2 (12): 1277-86.

[13] Moteki, H., Hibasami, H., Yamada, Y., Katsuzaki, H., Imai, K., and Komiya, T. 2002. "Specific Induction of Apoptosis by 1,8-Cineole in Two Human Leukemia Cell Lines, But Not a in Human Stomach Cancer Cell Line.” Oncol. Rep. 9: 757-60. Sandberg, F., and Corrigan, D. 2001. Natural Remedies: Their Origins and Uses. London: CRC Press.

[14] Bajalan, I., Rouzbahani, R., Pirbalouti, A. G., and Maggi, F. 2017. "Chemical Composition and Antibacterial Activity of Iranian lavandulahybrida”. ChemBiodivers14(7).dx.doi.org/10.1002/cbdv.201700064

[15] Kazemzadeh, R., Nikjou, R., Rostamnegad, M., and Norouzi, H. 2016. "Effect of Lavender Aromatherapy on Manopause Hot Flushing: A Crossover Randomized Clinical Trial." Journal of the Chinese Medical Association 79: 489-92.

[16] Allahverdiyev, A., Duran, N., Ozguven, M., and Koltaş, S. 2004. "Antiviral Activity of the Volatile Oils of Melissa officinalis L. against Herpes Simplex virüs Type-2.” Phytomedicine 11: 657-61.

[17] Canadanovic-Brunet, J., Cetkovic, G., and Dijilas, S.
2008. "Radical Scavenging, Antibacterial, and Antiproliferative Activities of Melissa officinalis L. Extracts.” J. Med Food 11: 133-43.

[18] Hasanein, P., and Riahi, H. 2015. “Antinociceptive and "Antihyperglycemic Effects of Melissa officinalis Essential Oil in an Experimental Model of Diabetes.” Medical Principles and Practice 24: 47-52.

[19] Gulluce, M., Sokmen, M., Sahin, F., Sokmen, A., Adiguzel, A., and Ozer, H. 2004. "Biological Activities of the Essential Oil and Methanolic Extract of Micromeria fruticosa (L) Druce ssp serpyllifolia (Bieb) $\mathrm{pH}$ Davis Plants from the Eastern Anatolia Region of Turkey.” J. Science of Food and Agriculture 84: 735-41.

[20] Zheljazkov, V. D., Callahan, A., and Cantrell, C. L. 2008. "Yield and Oil Composition of 38 Basil (Ocimum basilicum L.) Accessions Grown in Mississippi.” J. Agric Food Chem. 56 (1): 241-5.

[21] Lachowicz, K. J., Jones, G. P., Briggs, D. R., Bienvenu, F. E., Palmer, M. V., Mishra, V., and Hunter, M. M. 1997. "Characteristics of Plants and Plant Extracts from Five Varieties of Basil (Ocimum basilicum L.) Grown in Australia.” J. Agric. Food Chem. 45: 2660-5.

[22] Korucu, B. 2009. "The Development of a Mew Contact Dryer and Determination of Its Performance of Drying Basil Determination (Ocimum basilicum L.).” Master Thesis, G.O.U Graduate School of Natural and Applied Sciences, Eskisehir.

[23] Celebi, C. 2010. "Phenolic Composition and Antioxidant Activity of Basil (Ocimum basilicum).” Master Thesis, AU Graduate School of Natural and Applied Sciences, Ankara.

[24] Aslan, D. F. 2014. "Determination of the Ontogenetic and Morphogenetic Variability in Different Basil (Ocimum basilicum L.) Gene Types.” Master Thesis, Adna Menderes University Graduate school of Natural and Applied Sciences, Aydın, Turkey.

[25] Bajpai, V. K., Sharma, A., and Baek, K. H. 2013. "Antibacterial Mode of Action of Cudrania tricuspidata Fruit Essential Oil, Affecting Membrane Permeability and Surface Characteristics of Food-Borne Pathogens." Food Control 32: 582-90.

[26] Luís, Â., Duarte, A. P., Pereira, L., and Domingues, F. 2017. "Chemical Profiling and Evaluation of Antioxidant and Anti-microbial Properties of Selected Commercial Essential Oils: A Comparative Study.” Medicines 4 (2): 36.

[27] Taherpour, A., Maroofi, H., Rafie, Z., and Larijani, K. 2012. "Chemical Composition Analysis of the Essential oil of Melissa officinalis L. from Kurdiatan, Iran by HS/SPME Method and Calculation of the Biophsicochemical Coefficients of the Components.” Natural Product Research: Formerly Natural Product 


\section{Chemical Composition and Antimicrobial Activity of Essential Oils of Ocimum basilicum var. album (L.) 471}

Benth, Lavandula angustifolia subsp. Angustifolia, Melissa officinalis Belonging to Lamiaceae Family

Letters 262: 152-60.

[28] Hawley, G. G. 1997. Condensed Chemical Dictionary (13th ed.). New York: Van Nostrand Reinhold.

[29] Karasova, G., and Lehotay, J. 2005. "Chromatographic Determination of Derivatives of p-Hydroxybenzoic Acid in Melissa officinalis by HPLC.” J. Liq. Chromatogr. 28: 2421-31. (sil)Riahi, L., Elferchichi, M., Ghazghazi, H., Jebali, J., Ziadi, S., Aouadhi, C., et al. 2013. "Phytochemistry, Antioxidant and Antimicrobial Activities of the Essential Oils of Mentha rotundifolia L. in Tunisia.” Ind. Crops. Prod. 49: 883-9.

[30] Monographs, E. 2003. The Scientific Foundation for Herbal Products, 2nd ed. New York: Thieme.

[31] Nurzynska-Wierdak, R., Bogucka-Kocka, A., and Szymezak, G. 2014. "Volatile Constituents of Melissa officinalis Leaves Determined by Plant Ege.” Nat. Prod. Commun 9 (5): 152-60.

[32] Sarer, E., and Kokdil, G. 1991. "Constituents of the Essential Oil from Melissa officinalis.” Planta Medica 57: 89-90.

[33] WHO. 1999. World Health Organization. Monographs on Selected Medicinal Plants. 1, Geneva.

[34] Lippincott, W. 2000. "Commission E Monographs, Herbal Medicine, Integrative Medicine Communications.” Edition American Botanical Council, Austin.

[35] Leung, A. Y., and Foster, S. 2003. Encyclopedia of Common Natural Ingredients Used in Food, Drugs and Cosmetics. New York: John Wiley and Sons.WHO. 1999. World Health Organization. Monographs on Selected Medicinal Plants. 1, Geneva.

[36] Bahtiyarca, R., and Bagdat, B. C. 2006. “The Essential
Oil of Lemon Balm (Melissa officinalis L.), Its Components and Using Fields.” J. Fac. Agric. 21 (1): 116-21.

[37] Suschke, U., Sporer, F., Schneele, J., Geiss, H. K., and Reichling, J. 2007. “Antibacterial and Cytotoxic Activity of Nepeta cataria L., N. cataria var. citriodora (Beck.) Balb. and Melissa officinalis L. Essential Oils.” Nat. Prod. Commun 2 (12): 1277-86.

[38] Mimica-Dukic, N., Bozin, B., Sokovic, M., and Simin, N. 2004. "Antimicrobial and Antioxidant Activities of Melissa officinalis L. (Lamiaceae) Essential Oil.” J. Agric. Food Chem. 52: 2485-9.

[39] Jianu, C., Pop, G., Gruia, A. T., and Horbat, F. G. 2013. "Chemical Composition and Antimicrobial Activity of Essential Oils of Lavender (Lavandula angustifolia) and Lavandin.” International Journal of Agriculture\&Biology 15 (4):772-6.

[40] Varona, S., Martin, A., Cocero, M. J. 2009. "Formulation of a Natural Biocide Based on Lavand in Essential Oil by Emulsification Using Modified Starches.” Chemical Engineering and Processing Process Intensification 48: 1121-8.

[41] Yap, P. S. X., Krishnan, T., Yiap, B. C., Hu, C. P., Chan, K. G., and Lim, S. H. E. 2014. "Membrane Disruption and Anti-quorum Sensing Effects of Synergistic Interaction between Lavandula angustifolia (Lavender Oil) in Combination with Antibiotic against Plasmid-Conferred Multi-drug-resistant Escherichia coli.” J. Appl. Microbiol. 116: 1119-28.

[42] Koulivand, P. H., Ghadiri, M. K., and Garji, A. 2013. "Lavender and the Nervous System." Evidence-Based Complementary Alternative Medicine, 681304. 